\title{
EL REGIONALISMO ES LO QUE LA ACADEMIA HACE DE ÉL
}

\author{
Regionalism is what scholars make of it
}

\section{Daniela Perrotta}

Instituto de Investigaciones en Ciencias de la Educación

Facultad de Filosofía y Letras

Universidad de Buenos Aires

danielaperrotta@gmail.com

https://orcid.org/0000-0003-1060-5129

\begin{abstract}
Emanuel Porcelli
Centro de Estudios en Ciudadanía, Estado y Asuntos Políticos (CEAP) Facultad de Ciencias Sociales Universidad de Buenos Aires eporcelli@gmail.com https://orcid.org/0000-0002-1364-6383
\end{abstract}

Recibido: $18 / 10 / 2018$

Aceptado: 19/12/2018

Resumen: Este artículo se propone deconstruir la categoría analítica de regionalismo de América Latina para iniciar una reflexión dentro del campo de estudios de la integración sobre la pregunta por la integración regional y el regionalismo. Primero, se analizan las dos redes centrales de conocimiento que han ejercido una presión normativa en los procesos políticos de construcción de región (praxis), así como de construcción de conocimiento (teoría). En segundo lugar, se aborda el problema de la adjetivación del regionalismo mediante la presentación de diferentes propuestas y se señalan sus potencialidades y desafíos. Tercero, se recupera un conjunto intencional de definiciones que permitan construir entendimientos mínimos comunes en torno al objeto de estudio. Sobre esta base, el artículo concluye con una propuesta de trabajo para este campo.

Palabras clave: regionalismo; integración; producción de conocimiento; decolonialidad. 


\begin{abstract}
This article aims to deconstruct the analytical category of regionalism in Latin America to initiate a reflection within the field of studies of regional integration centered in questioning what regional integration and regionalism are. First, we analyze the two central knowledge networks that have exerted a normative pressure on the political processes of region-building (praxis) as well as knowledge construction (theory). Second, we address the problem of the adjectives of regionalism by presenting the different proposals and highlighting their benefits and challenges. Third, we recover an intentional set of definitions that allow us to build common minimum understandings around our object of study. On this basis, the article concludes with a work proposal for the field of study.
\end{abstract}

Keywords: regionalism; integration; knowledge production; decoloniality. 


\section{Introducción}

El regionalismo en América Latina está en cuestión desde la praxis política, así como también desde la producción de conocimiento académico como categoría analítica para analizar el fenómeno. ${ }^{1}$ Por un lado, desde el año 2012 se evidencian tensiones internas y externas en los procesos de construcción de región que gravitaron de manera novedosa en el escenario político latinoamericano. Los efectos de la crisis global del año 2008 comienzan a sentirse, junto con el retroceso del boom de las commodities que había motorizado el dinamismo de los primeros dos lustros del siglo xxI; el escenario político comienza a virar hacia el restablecimiento de gobiernos neoliberales, tanto por la vía electoral como de interrupción democrática; $y$, en este marco, se lanzan nuevas iniciativas regionales y megarregionales que marcan una ruptura y oposición respecto de los proyectos del regionalismo encaminado en el marco de la hegemonía progresista.

Así, especialmente, proyectos regionales como la Unión de Naciones Suramericanas (Unasur), la Comunidad de Estados Latinoamericanos y Caribeños (Celac) y —en menor medida- el Mercado Común del Sur (Mercosur) comienzan a ser disputados internamente por la modificación de la correlación de fuerzas de los escenarios nacionales y, externamente, en una nueva geopolítica regional, hemisférica y global que presenta a la Alianza del Pacífico (AP) y al Tratado del Transpacífico de Cooperación Económica (TTP) como alternativas más eficientes y acordes al nuevo contexto. Se genera una supuesta brecha entre un eje Atlántico y un eje Pacífico de integración que señala como sobreideologizado (bolivariano) al primero y moderno al segundo (Sanahuja, 2016). En el año 2018 el escenario se complejiza aún más con la crisis política en Unasur, la pérdida de gravitación de la Celac y un Mercosur que ha orientado su perfil a los lineamientos actuales, mas cuenta con capacidad de resiliencia en ciertas agendas.

Por otro lado, hay un problema en la construcción de conocimiento académico respecto a cómo se ha abordado el regionalismo y la integración regional durante la fase de los gobiernos progresistas, y que se agrava en la fase actual de resurgimiento de los gobiernos conservadores. A partir del año 2008 se encuentra un inconveniente en el campo de estudios respecto a cómo analizar y teorizar el regionalismo y la integración regional en América Latina - como parte de cierta agitación conceptual (Perrotta, 2012, 2018) de los paradigmas dominantes-, que se expresa en cómo tratar los nuevos proyectos de construcción de región. Puntualmente, por esos años la transformación de la Comunidad Sudamericana

1 Si bien se hace referencia a América Latina, este trabajo tiene un sesgo hacia América del Sur, ya que — solamente con algunas cuestiones puntuales que se señalan — no se abordan integralmente los procesos de construcción de región en México, Centroamérica y Caribe. 
de Naciones (CSN) en Unasur, la radicalidad de la propuesta de la Alternativa Bolivariana para los Pueblos de Nuestra América - Tratado de Comercio de los Pueblos (ALBA-TCP) y, más adelante en el tiempo, la creación de la Celac —que incorporaba nuevamente en el escenario de concertación política a México y Cuba - generaron desafíos conceptuales dada la novedad de las propuestas. Así, se popularizaron sus análisis, tanto en las redes centrales (mainstream) como en las redes periféricas de producción de conocimiento académico sobre integración regional, ya que las características de estos acuerdos no solo generaban curiosidad teórica, sino que, además, comienza a ser políticamente correcto escribir sobre regiones dependientes (configuradas como el Sur global).

Resulta llamativo que en este escenario el Mercosur no recibió - comparativamente- la misma atención que los acuerdos mencionados y que el estudio de sus dinámicas permaneció casi desconocido en la red mainstream, y quedó en una posición marginal aun dentro de la red periférica. En la actualidad, es posible observar un fenómeno inverso: quienes se quedaron sin objeto de estudio dado el cambio de contexto, han comenzado a descubrir el Mercosur y sus potencialidades. De repente, este acuerdo se ha vuelto un foco de análisis de académicos de la red central (o que buscan pertenecer a la red central aún en una posición subordinada) en términos de contribución a la gobernanza regional; mas este viraje hacia el estudio del Mercosur se realiza sin el reconocimiento de los trabajos de investigación rigurosos anteriores, que se encuentran invisibilizados en la red central de producción y divulgación de conocimiento académico.

Retomando la línea argumental, la respuesta teórico-conceptual que se generó como contestación al desafío de cómo asir los procesos de construcción de región en la América Latina de inicios del siglo xxI fue la proliferación de estudios del regionalismo desde su adjetivación. En otras palabras, se describieron y analizaron procesos a partir de agendas sectoriales o bien enfocando en su dimensión política — sin, necesariamente, la pretensión de una explicación integral—que derivó en el ensayo de una plétora de adjetivos para enmarcarlos, entre los que sobresalen al menos tres propuestas de abordaje del regionalismo: el posliberal, el poshegemónico y el estratégico. Consecuentemente, el regionalismo adjetivado (Perrotta y Porcelli, 2016b) es la marca distintiva de la producción de conocimiento sobre la integración regional en América Latina. Este movimiento permitió contar con categorías novedosas y productivas para describir procesos desde una cierta mirada centrada — más no necesariamente descolonizada - en y desde la región, pero no avanzó en la conformación de un marco teórico-conceptual y metodológico capaz de aportar sustantivamente a la pregunta-problema estructural y estructurante del campo de estudios desde sus inicios: ¿qué es la integración regional? 
En otras palabras, ¿se generaron marcos analíticos capaces de explicar otros procesos y no solamente la excepcionalidad latinoamericana? El regionalismo adjetivado prestó buena atención a la adjetivación, pero no se enfocó en profundidad en aquellos elementos que permiten afirmar que esos procesos son regionalismos - ya que se los tomó como dados; se partió del supuesto de que lo eran. En este movimiento se siguió profundizando la brecha teórica y de práctica política iniciada en los años noventa: la eliminación de la categoría integración regional dentro del campo de estudios, dada su sustitución por el concepto más laxo de regionalismo. El regionalismo adjetivado acentúo esta tendencia en América Latina, como parte de las dinámicas de producción y divulgación de la actual geopolítica del conocimiento. Al hacerlo, incurrió en el mismo error que se le atribuye a la escuela de las teorías de la integración europea (TIE): explicar un único caso $(n=1)$. Esto es, en la actualidad, un problema serio, porque esos mismos casos adjetivados ni siquiera están pudiendo ser explicados desde esos prismas.

Por lo tanto, este artículo busca deconstruir la categoría analítica de regionalismo de América Latina para proponer algunos elementos que permitan iniciar una reflexión dentro del campo de estudios de la integración sobre la pregunta por la integración regional y el regionalismo. En otras palabras, lo guía una meta teórica de deconstrucción y reconstrucción conceptual de las categorías de integración regional y regionalismo, que tiene como primer paso establecer una agenda de investigación. Para encaminar este proceso se propone un ejercicio analítico-reflexivo en tres instancias: primero, desentrañar las redes centrales de conocimiento académico a partir de las dos escuelas que prescriben los términos, y las formas de estudiar y evaluar estos procesos. El argumento es que las teorías de la integración europea (TIE) y las teorías del nuevo regionalismo (TNR) han ejercido una presión normativa tanto en los procesos políticos de construcción de región (praxis), como en los procesos de construcción de conocimiento (teoría) que han generado problemas de dependencia académica que se profundizan aceleradamente dada la actual geopolítica global del conocimiento. La Unión Europea (UE) ejerció (¿ejerce?) una presión normativa en dos niveles: la promoción de un modelo prescriptivo de hacer integración en los y las hacedores de política, y en la diseminación de propuestas teórico-metodológicas para asir otros procesos regionales en el mundo. En el caso de las TNR, la presión normativa se ejerce solamente en el plano del conocimiento académico e, incluso, en la actualidad es más fuerte esta presión que la que ejerce la escuela de las TIE, y ello se debe a la necesidad de legitimarse y validarse en esa comunidad epistémica y red mainstream.

En segundo lugar, se despliega el problema de la adjetivación del regionalismo mediante la presentación de las diferentes propuestas elaboradas para asir los procesos de la región para señalar sus potencialidades y desafíos. Especialmente, 
se busca dar cuenta de las falencias en términos de diferenciación analítica y delimitación conceptual (Collier y Levitsky, 1998) para reflexionar sobre la definición de la categoría. Finalmente, a partir de esas reflexiones, se recupera un conjunto intencional de definiciones que permitan construir entendimientos mínimos comunes en torno al objeto de estudio - destacando su carácter preliminar y provisorio, dada la necesidad de discutirlos en variados espacios institucionales (desde revistas académicas hasta reuniones científicas e instancias de formación). Sobre esta base, el artículo concluye con una propuesta de trabajo para el campo de estudio.

Vale destacar que este trabajo no se dedica a analizar los procesos de integración regional y regionalismo vigentes actualmente, sus configuraciones, sus desafíos y su prospectiva en un escenario en permanente modificación y disputa. El foco se coloca en la discusión teórica.

\section{El poder normativo de la red central de producción y divulgación de conocimiento del campo de estudios de la integración regional y el regionalismo}

La creación de esquemas de integración regional ha estado influenciada por dos modelos que adquirieron estatus distinguidos: el europeo ${ }^{2}$ y el regionalismo nuevo o abierto $^{3}$. Así, buena parte de los acuerdos regionales creados entre los años sesenta y principios de los noventa fueron sujeto de prescripciones respecto de su morfología y evaluados exhaustivamente en términos de cuánto se parecía o difería en relación con la experiencia de integración de Europa occidental. De la misma manera, el nuevo regionalismo prescribió la forma deseada de sortear los desafíos de una globalización competitiva desde mediados de los años noventa. El primero se diseminó como parte de la estrategia de política exterior de la actual Unión Europea (UE) (Allison, 2015; Börzel y Risse, 2000, 2009; Haastrup, 2013; Jetschke y Lenz, 2013). El segundo formó parte del repertorio de prescripciones de políticas de un conjunto de organismos financieros internacionales (Bhagwati y Panagariya, 1999; BID, 2002; De Melo y Panagariya, 1995; Frankel, Stein, y Wei, 1995; Panagariya, 1992). Mientras en el primero la nota distintiva

2 Las alusiones a Europa señalan a la actual Unión Europea.

3 Se hace referencia aquí al tipo histórico de regionalismo denominado como nuevo, para diferenciar de los primeros procesos de construcción de región (viejo regionalismo) y no a la corriente teórica homónima. También abordado como regionalismo abierto, especialmente en sus primeras formulaciones - como la de la propia Comisión Económica para América Latina y el Caribe (Cepal, 1990). 
versó en la cesión de soberanía en diversas agendas de política pública; el segundo se concentró en la regulación del comercio internacional para promover la liberalización de bienes, servicios, inversiones, propiedad intelectual y compras públicas (Perrotta, 2018).

Al mismo tiempo, estos dos modelos prescriptivos de construcción de región fueron analizados y evaluados a partir de modelos teóricos que ejercieron presión normativa sobre el campo de producción y divulgación de conocimiento. Consecuentemente, es posible afirmar que la UE ejerció una presión normativa en un doble nivel: al promover sobre el sector público gubernamental y otros actores interesados en este nuevo nivel de elaboración de políticas y regulaciones (élites económicas y, más tardíamente, sociedad civil organizada) diseños institucionales y recomendaciones de política por medio de mecanismos de difusión y de imposición; pero también, en el nivel cognoscitivo, influenciando comunidades epistémicas por medio de sus cátedras Jean Monnet, así como por su posición jerárquica en la ciencia mundial. Es decir, por su posición jerárquica en la red central de producción de conocimiento, eminentemente occidental y anglosajona.

En el caso del regionalismo abierto (RA) ${ }^{4}$, la presión de organizaciones internacionales y regionales fue mermando - en América del Sur- con las crisis económicas, sociales y políticas de fin de siglo y solamente fue la potencia hegemónica la que promovió estas recomendaciones en el marco de la negociación del Área de Libre Comercio de las Américas (ALCA) y, posteriormente, con la búsqueda de tratados de libre comercio (TLC). Es decir, no hubo un actor global con capacidad de agencia para presionar a partir de intereses e ideas, tal como lo hizo la UE. Ante esta ausencia, la autorregulación del sector académico sentó las bases para una diseminación de ideas prescriptivas (más bien, performativas) sin la intencionalidad explícita o buscada de erigir un proyecto de construcción de región. Se hace referencia aquí, a cómo las reglas de producción, evaluación y diseminación del conocimiento académico (especialmente, la investigación y la formación) constriñen a los actores (académicos y académicas) y determinan comportamientos que los y las llevan a buscar validarse y legitimarse en comunidades de referencia y, en este proceso, se abordan problemas cognitivos que son propios de una red mainstream, junto con sus formas de conceptualizarlos y de abordarlos metodológicamente. También se diseminan marcos de entendimiento globalmente, que gozan de legitimidad como ciencia de excelencia pero que no necesariamente dan cuenta de problemas (cognitivos) locales. Prima la autorre-

4 Se utiliza la categoría regionalismo abierto para diferenciar este modelo prescriptivo en el campo de la praxis política del nuevo regionalismo como categoría teórica, solo con fines de simplificar la narrativa del presente artículo. En la práctica no existe tal división. 
producción de los y las académicos, que rinden cuenta a sus sistemas científicos nacionales y, además, buscan posiciones de visibilización y prestigio en sus respectivos campos.

En este apartado se delimita, especialmente, en qué consiste ese poder normativo ejercido por la UE y que también se encuentra en el caso de la escuela de las TNR.

\subsection{El poder normativo de la UE y sus efectos sobre la construcción de conocimiento}

La influencia de la UE en la promoción de su proyecto de integración regional en diferentes partes del mundo se encuentra ampliamente estudiada, especialmente desde los trabajos que enfocan este problema desde dinámicas de difusión por imposición y disuasión con un fuerte sesgo en detectar los procesos de mímesis institucional. Han sido más bien recientes los trabajos que comienzan a abordar la discusión del poder normativo desde una postura crítica y que incluya la reflexión sobre la dimensión epistemológica. ${ }^{5}$ De esta vasta literatura se ha seleccionado un conjunto de aportes que abonan a el argumento aquí presentado, sobre el poder normativo e ideacional en el campo del conocimiento académico sedimentado en relaciones de poder asimétricas entre redes centrales y redes periféricas.

En primer lugar, se recupera una investigación reciente realizada por Laura Allison (2015): el punto central a desentrañar es en qué medida la UE tiene la capacidad de moldear (o contribuir a moldear) los asuntos internacionales desde ejes de análisis que no versen exclusivamente sobre el poder - ya que el ejercicio del poder no permite observar de manera adecuada la relación entre la UE y sus interlocutores. ${ }^{6}$ Sobre esta base, ella afirma que la combinación de los valores normativos de la UE con el

5 Esto se sistematiza en una línea de debate sobre el Normative Power Europe (NPE), donde se destaca el análisis crítico de Staeger (2016). El Normative Power Approach (NPA) — sobre el que se construye el NPE - estudia los fundamentos normativos del poder a través de una síntesis de enfoques históricamente contrapuestos: por un lado, el enfoque positivista en Relaciones Internacionales (RI) (que aborda el poder y los intereses) y, por otro, el enfoque reflectivista en RI (que estudia los valores y el conocimiento). La contraposición entre ambos enfoques deja sin respuesta la cuestión de cómo entender las interrelaciones entre las formas de poder material y no material. El NPA se erige como una alternativa para saldar esa contraposición dicotómica (Manners, 2015).

6 Puntualmente se está discutiendo con la postura de Thomas Diez (2005), quien afirma que el poder normativo no difiere sustancialmente del poder militar porque se pueden utilizar medios militares para apoyar la difusión de valores no militares. Para Manners (2006) el uso del poder militar y el desarrollo de capacidades militares tienen la capacidad de socavar el poder normativo de la UE y simplemente proyectar las tensiones entre los estados a una escala mayor. Adicionalmente, el poder normativo permite fortalecer simultáneamente el derecho internacional y el derecho cosmopolita al reconocer y apoyar los derechos de los individuos así como los derechos de los Estados (Sjursen, 2006). 
ejercicio de poder ha creado una imagen ambigua y distorsionada de su capacidad de agencia (actorness, lo que impide una explicación precisa de lo que la UE ha realizado (Allison, 2015, p. 7). De esta manera, el análisis del poder normativo de la UE ha de ser doble: por un lado, comprender el proceso de difusión de normas (Manners, 2002), y por el otro, examinar el rol de promotora de normas de la UE y los marcos de localización y subsidiaridad de la norma (Acharya, 2004, 2011). En el caso de la autora, lo aborda para comprender procesos de difusión de normas y de apoyo al regionalismo entre la UE y la Asociación de Naciones del Sureste Asiático (ASEAN).

Comprender el poder normativo bajo estos criterios implica revisitar un conjunto de referencias teóricas. Para comenzar, si bien Manners (2008) argumenta que «una cosa es decir que la UE es un poder normativo en virtud de su política híbrida que consiste en formas de gobierno supranacionales e internacionales; otra es argumentar que la UE actúa de manera normativa (es decir, de manera éticamente buena)» (Manners, 2008, p. 45); se omite reconocer que la UE es un poder normativo como consecuencia de los resultados de sus acciones, pero también cómo es percibida como tal por otros actores. ${ }^{7}$ Por lo tanto, es menester analizar la perspectiva de esos interlocutores sobre aquellos que experimentan el poder normativo de la UE. Su trabajo pone en jaque algunos argumentos establecidos: en primer lugar, que la UE tiene la capacidad de cambiar lo que es normal y aceptado en otro contexto en el caso de las normas políticas, por otra parte, su trabajo de campo muestra que han sido las normas técnicas relacionadas a la integración económica las que mayor impacto generaron en su caso — en vez de las normas políticas. Segundo, en lo que respecta a valores éticos, su caso muestra que se han diseminado de manera más exitosa las normas específicas de la UE y no tanto las universales - puntualmente, no se observa una acción consiste de la UE en el caso de normas vinculadas a derechos humanos. Así, «si bien desde una ética deontológica y de las consecuencias no se cuestiona la promoción que hace la UE del regionalismo hacia la ASEAN, [los] hallazgos demuestran que la [propia] conceptualización como poder normativo es contestada» (Allison, 2015, p. 26).

En segundo término, Michael Merlingen argumenta que el poder normativo de la UE tiene dos aristas: por un lado, sus proyectos buscan «limitar la degradación y la humillación de los individuos, pero por otro lado, también somete los órdenes locales a las pretensiones universalistas de Europa» (2007, p. 449). Adicionalmente, es posible observar dos lados del poder: si bien, en un aspecto, «hu-

7 En efecto, Diez (2005) discute el poder normativo en relación con la identidad al afirmar que el discurso que rodea al poder normativo - y el poder normativo de Europa en particular - colabora en la construcción de la identidad de la UE, así como en la identidad de otros en relación con la UE. Manners (2002) en cambio indica que la UE es un actor distinto debido a su propia naturaleza normativa y al uso del poder normativo. 
maniza y mejora la vida de las poblaciones, también crea patrones de dominación arbitraria entre los internacionales y los locales» (Merlingen, 2007, p. 449). No obstante, esta doble arista del poder normativo (y del poder, en general) ha generado para Manners (2015) falsas dicotomías entre la sociología del conocimiento sobre la UE y la producción de las acciones exteriores de la UE. En sus términos, por «falsas dicotomías se refiere a los intentos de dicotomizar falsamente [...] entre el valor neutro positivo frente a la ciencia política normativa; y entre el poder normativo y el poder normal»(Manners, 2015, p. 301). Para saldar esta postura, propone analizar el poder normativo de la UE desde el policy-making, así como desde el policy analysis. Su trabajo permite ilustrar cómo las ideas sobre las acciones externas se difunden desde el estudio del poder normativo a otros marcos normativos, y desde los analistas hasta los responsables políticos en el campo de las acciones externas de la UE. Esto le permite afirmar que «la dicotomización estratégica y la difusión social [... hacen que Europa] sea normal» (Manners, 2015, p. 301). Consecuentemente,

Lo que demuestra la difusión social de las ideas del poder normativo en otros marcos, así como más allá de la comunidad académica, es que la difusión social es una norma de las ciencias sociales. Si bien tanto la dicotomización estratégica como la difusión social se encuentran en los mundos académicos, del análisis político [policy-analysis] y del policy-making, ambas son prácticas normales y hacen que Europa sea normal en el sentido de la práctica social. Más importante aún, para aquellos que se involucran en estas prácticas sociales normales, tanto la dicotomización estratégica de poder normativo frente al poder normal como la difusión social del conocimiento y la producción de políticas, son procesos normativos con consecuencias normativas para las acciones externas de la UE. Solo mediante la adopción de un enfoque de la sociología reflexiva del conocimiento [es posible] comprender la idea del poder normativo [y así] entender el poder que tienen estos procesos y sus consecuencias normativas para el conocimiento y la producción del poder normativo en las acciones externas de la Unión Europea. (Manners, 2015, p. 315)

Esta discusión sobre el poder dentro del poder normativo permite incorporar un tercer aporte teórico, desde una perspectiva decolonial. ${ }^{8}$

Finalmente, se coincide con Staeger (2016) en que el debate sobre el NPE, simplemente entendido como un debate sobre la dicotomía entre normas e intereses ${ }^{9}$,

8 El autor utiliza decolonial para aludir a la prescripción que realiza la academia anticolonial para superar la condición poscolonial. Mientras poscolonial refiere a la descripción del proceso incompleto de descolonización europeo y la dominación del conocimiento europeo (Staeger, 2016).

9 El autor alude a la clasificación epistemológica propuesta por Manners (2002, p. 252) que ordena el debate académico sobre el NPE en función de su objeto de análisis: así se encuentran trabajos con un enfoque ontológico (la UE como un actor que tiene capacidad de producir y modificar algunas las normas del sistema internacional); positivista (cómo la UE realiza un proceso de difusión de normas); y normativo (cómo la UE debe actuar externamente para difundir sus normas). 
sigue reproduciendo el carácter neocolonial (Staeger, 2016, p. 986) ya que, aunque se presente con un grado de conciencia básica sobre el rol de la hegemonía europea (y un discurso poscolonial de superficie), no renuncia a cierto grado de (falso) universalismo neokantiano asociado a principios universales.

Si bien el debate sobre el NPE hace referencias al pasado colonial europeo (el autor trabaja esta cuestión en el caso africano), continúa presentando una temporalidad lineal de modernidad en donde ubica al pasado europeo (colonial, nacionalista, autoritario, responsable del holocausto) como una etapa anterior (inferior, atrasada) en donde se violaron esos principios universales deseables. Ese Otro aparece en el debate del NPE como el propio desgraciado pasado europeo y como un mal anacrónico actualizado aplicable a la realidad africana ( $\mathrm{y}$ latinoamericana?).

Staeger afirma que el NPE es neocolonial, ya que carece de legitimidad para exportar su normatividad. El razonamiento es perfectamente circular: porque las normas europeas (o en nuestro caso, el modelo deseable de regionalismo) son supuestamente universales, se convierte en una herramienta discursiva permanente para señalar las deficiencias del Otro (en este caso, África) que recuerda una relación de superioridad automática similar al paternalismo colonial en donde el conocimiento y lugar del Otro ocupa un papel subsidiario o residual (Staeger, 2016, p. 987).

Resulta relevante entonces, poder analizar la capacidad normativa de la UE (en tanto actor como ejemplo a alcanzar) desde el prisma deconstructivista — como lo denominó Derrida - buscando desnaturalizar las dicotomías arraigadas y los significados de la posición privilegiada de uno de ellos (del par binario) sobre el otro (bien/mal - Occidente/Oriente). Sin estas relaciones binarias, el desarrollo de la verdad positivista pierde su posición privilegiada en todo el proceso de producción de conocimiento (Der Derian, 1989, p. 4). Analizar, en función del objetivo central de este trabajo, la presunción de la preferencia de entramados institucionales supranacionales como forma deseable para la integración regional es una demostración de este fenómeno.

\subsection{Las presiones (normativas) ocultas de las teorías del (nuevo) regionalismo}

Las discusiones señaladas en el acápite anterior dan cuenta de que, efectivamente, las TIE son las que más han influenciado el estudio y la evaluación de la integración en otras partes del globo. No obstante, al menos desde el siglo actual, se pone en duda que siga siendo la UE la que ejerce presión normativa sobre la praxis 
y sobre la teoría. ${ }^{10}$ En efecto, como se observará en la sección que sigue, la construcción de conocimiento estuvo permeada por las propuestas generadas por las TNR. Así como en el caso europeo existen las reflexiones mencionadas sobre las presiones que ejerce; no se ha desarrollado una discusión similar para la incidencia de las TNR y sus formulaciones sobre el regionalismo desde perspectivas no anglocéntricas -0 mejor dicho, desde perspectivas que se nutran de reconocer la geopolítica del conocimiento y las relaciones de poder entre centros y periferias en este campo. Puntualmente, existen pocos trabajos que recuperen la necesidad de analizar el regionalismo y la integración desde posturas decoloniales en América Latina - exceptuando los trabajos de Vivares y Dolcetti-Marcolini (2016); Vivares, Lombardo, y Cvetich (2014)-; o que excedan la propuesta de avanzar en el regionalismo comparado como única salida - lo que en este artículo es contribuir a la reproducción de presiones normativas por otras vías, salvo ciertos recaudos-(salvo Mattheis, 2017); y, aún más, escasean lecturas feministas para el estudio de los procesos de construcción de región.

Sobre esta base, se realizan algunas afirmaciones. En primer término, buena parte de lo que se indica como crítica a las TIE en el estudio de otras regiones como América Latina, puede ser aplicado como crítica a las TNR. El trabajo de Vivares y Dolcetti-Marcolini (2016) postula cuatro rasgos que las jaulas de hierro conceptuales (Vivares y Cvetich, 2014) de la integración europea imprimen al regionalismo como concepto y como proceso real: 1. siguen un paradigma integracionista haasiano en el que el regionalismo es sinónimo de integración, y esto deriva en que se cede soberanía a instituciones supranacionales y donde la integración económica prima sobre otras agendas; 2. son modelos interpretativos deterministas y lineales en los que la integración es el resultado de una sucesión histórica entre etapas claramente diferenciadas; 3. priman objetivos de convergencia y homogeneidad entre países, sociedades e instituciones y minimizan procesos de cambio y transformación de los órdenes regionales y mundiales; 4. tienen pretensión de universalidad a partir de cierta neutralidad valorativa u objetividad (Vivares y Dolcetti-Marcolini, 2016).

Todo esto es válido para las TIE - si bien es posible argumentar que el propio Haas cuestionó la idea de linealidad de la integración y de que sus conceptos eran útiles y pertinentes para otras realidades (Haas, 1976) - pero además lo es para las TNR: la idea de niveles de regionidad (Hettne y Söderbaum, 2002) o las categorías que componen el regionalismo para Hurrell (1995a) también tienen componentes deterministas por acumulación de estadios y, por sobre todo, pre-

10 Se justifica esta afirmación de manera provisoria a partir de haber analizado la producción sobre regionalismo/integración en América Latina en otro trabajo (Perrotta, 2018), donde destacan las conceptualizaciones de regionalismo en detrimento de las TIE. 
tensión de universalidad. Además, si se considera que las TNR tienen un fuerte sustrato disciplinar de la economía política internacional (EPI), es posible afirmar cierta primacía del elemento económico como central en el análisis; si bien hay posturas de las EPI críticas que despliegan más dimensiones de análisis dada la multiplicidad y heterogeneidad de actores.

En segundo lugar, la búsqueda de diálogo entre las TIE y las TNR derivó en tres estrategias: el regionalismo comparado, el interregionalismo y el regionalismo descentrado (Mattheis, 2017). Las dos primeras siguen reproduciendo el patrón de conocimiento que se señaló en el acápite anterior. El primero, por el énfasis a la comparación en sí misma sin discutir qué es el objeto para comparar y donde han primado las miradas de las TIE; el segundo, porque cuando se genera la propuesta surge en un esquema de rayos y ejes donde el centro es la UE. La tercera estrategia deja un espacio mayor para la incorporación de miradas del regionalismo combinadas con la crítica al patrón moderno/colonial de conocimiento, ya que se «propone descentralizar el regionalismo al observar las lógicas generalizables del regionalismo sin negar las diferencias que apuntan a características contextualizadas» (Mattheis, 2017, p. 2). Se parte de un enfoque no idiosincrático y adaptable a las diferentes realidades, pero alertando que cada regionalismo no ha de tratarse como un fenómeno único porque ello tampoco es productivo para trasladar categorías a otras experiencias. Esta aclaración va en línea con el planteo de no enfocar exclusivamente la adjetivación (la diferencia) para poder generar los consensos mínimos del objeto que sean susceptibles de tender puentes de entendimiento entre enfoques teóricos. Entre los trabajos que plantean esta estrategia se señala a Bach (2015) — quien aborda África y construye conceptos aplicables a otras experiencias - y al reciente trabajo de Söderbaum (2016) de repensar el regionalismo, si bien no abre sustantivamente el abanico de la discusión a perspectivas como las que aquí se claman.

Tercero, el aporte de una mirada decolonial ya ha sido analizado en el caso de las TIE y el poder normativo de la UE. Solo se destaca aquí que, para América Latina y en vistas a dialogar con las diferentes disciplinas para el estudio de la integración, el trabajo de Vivares y Dolcetti-Marcolini (2016) da el puntapié inicial para su visibilización.

Finalmente, la preeminencia oculta de las TNR en el estudio del regionalismo en América Latina - cuya consecuencia directa, a modo de estrategia de diferenciación es la adjetivación — se debe a las producciones de conocimiento actuales que constriñen a la academia a investigar determinados asuntos, desde determinados conceptos, con determinadas metodologías para ser visibilizados en un determinado circuito de divulgación: el mainstream. De esta manera, se replican al infinito los trabajos que utilizan los mismos marcos y categorías sin 
poder criticarlos o superarlos; mientras que la forma de ganar originalidad es creando adjetivos capaces de popularizarse y así ganar validez y legitimidad en la comunidad académica. Este proceso, en la actualidad, está incidiendo más sobre las formas de producción de conocimiento que lo que la propia UE en tanto actor realiza. Precisamente, porque los y las teóricos de las TNR son parte de ese circuito central de conocimiento de excelencia.

\section{La producción académica sobre la integración regional en América Latina: el regionalismo adjetivado en cuestión}

Dar cuenta qué es (y qué no es) la integración regional - y, más adelante, el regionalismo - es la preocupación y el desafío central de este campo de estudios desde sus inicios; especialmente, al hacer referencia a un objeto de estudio complejo y multidimensional que no puede asirse como si fuera un mega Estado — si bien comparte características de estatidad que son posibles de diseccionar (Warleigh-Lack y Van Langenhove, 2010). A raíz de esta complejidad, el campo de estudios se fue desarrollando a partir de la observación y el análisis de diferentes aristas del proceso, como parte de una estrategia de construcción de teorías de alcance medio que fueran capaces de abrevar más adelante — según se esperaba- en una (o unas) teoría(s) general(es). Este camino fue sinuoso y en varias coyunturas críticas del proceso de construcción de conocimiento — generalmente coincidentes con modificaciones en los acuerdos regionales - se han discutido estas estrategias de generación de teorías, enfoques y metodologías: desde la discusión de Puchala (1971) sobre hombres ciegos y elefantes, hasta la búsqueda del diálogo entre los dos circuitos centrales de Warleigh-Lack y Van Langenhove (2010), entre otros. Sobre esto último, lo que se ha postulado para cerrar la grieta son los estudios del regionalismo comparado (Söderbaum y De Lombaerde, 2013; Warleigh-Lack, 2006; Warleigh-Lack y Van Langenhove, 2010), aunque también existen detractores de esta estrategia — como Closa (2015).

Tal como se afirmó en la sección precedente, las relaciones asimétricas de poder entre la producción y divulgación de conocimiento académico a nivel global han generado un poder normativo de las redes centrales que presionan sobre redes de conocimiento periféricas y dependientes. La producción de conocimiento en América Latina no ha permanecido exenta de estas dinámicas: ni en el período de la integración regional de los años sesenta ni con la reformulación hacia la prescripción del regionalismo abierto en los noventa ni, mucho menos, con el inicio del siglo XXI y la diseminación de las TNR como parte de la internacionalización de la ciencia y la universidad. Enfocando solamente este último período, se evidencia un fenómeno de adjetivación del regionalismo a modo de intento 
de rescatar las peculiaridades de los procesos gravitantes de construcción de región iniciados en este momento. Se destacan tres propuestas de análisis de los procesos de construcción de región en Latinoamérica - posliberal, estratégico y poshegemónico-, así como otras conceptualizaciones más específicas y menos popularizadas.

\subsection{Regionalismo posliberal}

Esta categoría parte del análisis sobre la especificidad de la política latinoamericana con el cambio de siglo: especialmente, la crisis del proyecto neoliberal y la llegada al poder de nuevos gobiernos - con amplio apoyo popular y movilización social—, que ensayaron estrategias diferentes para encaminar una nueva senda de desarrollo integral. Por lo tanto, estas primeras formulaciones del tipo de regionalismo estuvieron permeadas por la profusa producción teórica sobre como nominar este nuevo momento o ciclo de América Latina: una nueva izquierda, el retorno del progresismo, gobiernos neodesarrollistas, populismo y socialismo del siglo XXI, etc. ${ }^{11}$

Consecuentemente, en este escenario de procesos políticos con matices entre sí, la propuesta de regionalismo posliberal de Motta Veiga y Ríos (2007) habilita al menos dos casos: la Comunidad Sudamericana de Naciones (CSN, antecedente de la Unasur) y la del ALBA, uno desarrollista y otro antiliberal. Los autores afirman que la hipótesis básica de este concepto es que la liberalización de los flujos comerciales y de las inversiones, junto con su consolidación en acuerdos comerciales, no permitió generar beneficios endógenos para el desarrollo pero que, aun así, es posible que logren reducir el espacio para la implementación de políticas nacionales desarrollistas y adoptar una agenda de integración orientada a la equidad. Entonces, entre las agendas que se abren en este marco se encuentra tanto la plétora de asuntos económicos no comerciales, como agendas sociales y de participación. Esto es expresión de las nuevas agendas de política doméstica de estos gobiernos, marcada por la crítica al neoliberalismo, el resurgimiento de cierto nacionalismo económico y una mayor gravitación de los asuntos políticos por sobre los económicos en la política exterior.

Sobre esta idea, Sanahuja (2008) caracteriza con mayor precisión este tipo de regionalismo:

a. La primacía de la agenda política, y una menor atención a la agenda económica y comercial, lo que no es ajeno a la llegada al poder de distintos gobiernos de izquierda, al tono marcadamente nacionalista de

11 Sobre estas ideas, véase: Vilas (2005, 2008), Sader (2009), Laclau (2006), Moreira, Raus, y Leyton (2008) y Aboy Carlés (2004), entre otros. 
esos gobiernos, y a los intentos de ejercer un mayor liderazgo en la región por parte de algunos países, en particular Venezuela y Brasil.

b. El retorno de la agenda de desarrollo, en el marco de las agendas económicas del pos Consenso de Washington, con políticas que pretenden distanciarse de las estrategias del regionalismo abierto, centradas en la liberalización comercial.

c. Un mayor papel de los actores estatales, frente al protagonismo de los actores privados y las fuerzas del mercado del modelo anterior.

d. Un énfasis mayor en la agenda positiva de la integración, centrada en la creación de instituciones y políticas comunes, y en una cooperación más intensa en ámbitos no comerciales, lo que, como se indicará, ha dado lugar a la ampliación de los mecanismos de cooperación sur-sur, o la aparición de una agenda renovada de paz y seguridad.

e. Mayor preocupación por las dimensiones sociales y las asimetrías en cuanto a niveles de desarrollo, y la vinculación entre la integración regional y la reducción de la pobreza y la desigualdad, en un contexto político en el que la justicia social ha adquirido mayor peso en la agenda política de la región.

f. Mayor preocupación por los cuellos de botella y las carencias de la infraestructura regional, con el objeto de mejorar la articulación de los mercados regionales y, al tiempo, facilitar el acceso a mercados externos.

g. Más énfasis en la seguridad energética y la búsqueda de complementariedades en este campo.

h. La búsqueda de fórmulas para promover una mayor participación y la legitimación social de los procesos de integración (Sanahuja, 2008, p. 22-23).

Al igual que los primeros, Sanahuja reconoce la vinculación con los procesos políticos nacionales e indica las diferencias entre la ya creada Unasur y el ALBA, reconociendo que la caracterización permite identificar sus peculiaridades, pero que el mapa de la integración en Latinoamérica es más heterogéneo. En textos posteriores - como Sanahuja $(2012,2016)$ - el foco ya se coloca sobre Unasur, dada la preeminencia de agendas de política, social, defensa y seguridad.

Finalmente, Riggirozzi (2012); Riggirozzi y Tussie (2012) se refieren al regionalismo posneoliberal para aludir al mismo proceso, como parte de un escenario complejo en el que se encuentra un escenario posneoliberal y otro poshegemó- 
nico. No obstante, por un lado, no difieren sustancialmente de la caracterización realizada por los otros autores y, por el otro, el regionalismo posneoliberal es subsumido en la caracterización de regionalismo poshegemónico, dejando fronteras analíticas un tanto borrosas para su delimitación y precisión.

\subsection{Regionalismo estratégico}

Esta categorización presenta algunas dificultades analíticas en torno al proyecto de construcción de región que busca explicar. En términos generales, la definición aborda estos procesos en el marco de la reconfiguración del poder mundial en los años noventa. Así, la idea de estratégico se vincula a la política comercial estratégica de los Estados desarrollados de promover un regionalismo que genere beneficios para sus empresas transnacionales (ETN) y del que puedan participar también aquellas empresas nacionales que iniciaron su proceso de internacionalización (Briceño-Ruiz, 2010). Esta categoría se podría utilizar tanto para el Tratado de Libre Comercio de América del Norte (TLCAN) (Briceño-Ruiz, 2010), como para la negociación del Área de Libre Comercio de las Américas (ALCA) (Briceño-Ruiz, 2007), donde el objetivo es aprovechar las ventajas comparativas de los países en el mercado internacional.

Lincoln Bizzozero (2011) utiliza la idea de regionalismo estratégico de manera similar al analizar al Mercosur como instrumento estratégico tanto del modelo liberal que lo inspiró, como en la reconfiguración de los escenarios nacionales con la crítica neoliberal. El regionalismo estratégico del siglo XXI se entiende a partir de la continuidad de la prioridad en las políticas exteriores de mejorar la posición internacional de Argentina y Brasil, pese a la importancia que comienzan a adquirir por entonces las agendas políticas y sociales de integración (Bizzozero, 2011, p. 32). Lo estratégico refiere de manera reducida al interés estratégico de los Estados gravitantes del bloque regional (en línea con el planteo de Briceño-Ruiz que se nutre de los aportes de Deblock y Brunelle (1993) y, en este sentido, no ve grandes líneas de ruptura entre el proyecto económico-comercial del Mercosur inicial y de su reconfiguración desde el Consenso de Buenos Aires del 2003.

Maribel Aponte (2015) realiza un análisis un tanto disruptivo para caracterizar al ALBA-TCP como nuevo regionalismo estratégico, al combinar aportes de la TNR en lo que refiere al regionalismo multidimensional y a los constructos de soberanía e identidad geopolítica con el regionalismo estratégico, y pasando de la gravitación de las ETN a la de las grannacionales. Este proceso es una instancia de regionalismo estratégico ya que se manifiestan alianzas entre Estados, empresas regionales (grannacionales) y empresas estratégicas (como PDV-SA) (2015, p. 25); 
es multidimensional porque se concretan múltiples redes entre las que se identifican «empresariales, [...] entre las Misiones y las empresas, [...] público-privadas y [...] entre organizaciones a nivel de los proyectos grannacionales» (2015, p. 27); y en el que la soberanía es crucial.

En suma, el foco común a las tres explicaciones refiere al rol que tiene el sector empresarial en el marco del interés de los Estados que conducen y acompañan los procesos de integración regional. Las variantes en la definición de qué es lo estratégico se enmarca en los proyectos políticos nacionales que predominan en diferentes momentos.

\subsection{Regionalismo poshegemónico}

Esta caracterización fue desarrollada por Riggirozzi y Tussie (2012) para abordar la Unasur y, especialmente, agendas sectoriales de políticas regionales dinámicas - como la salud - o bien rupturistas - como la defensa. El punto de partida para su observación refiere a los mismos cambios contextuales del cambio de siglo en la región: la contestación al neoliberalismo (el escenario posneoliberal que es, a la vez, un escenario poscomercial) y una debilitación de la hegemonía norteamericana (escenario poshegemónico). Ello permite que este nuevo tipo de regionalismo sea la expresión de la «manifestación visible de una repolitización en la región que está dando a luz a nuevas formas de hacer política y de proyectos regionales en los que Estados, movimientos sociales y líderes interactúan y construyen nuevos entendimientos sobre el espacio regional» ( $\mathrm{Ri}$ ggirozzi y Tussie, 2012, p. 3). Lo poshegemónico alude, pues, a estructuras regionales que son prácticas híbridas como resultado del desplazamiento parcial de las formas dominantes de la gobernanza neoliberal liderada por los Estados Unidos hacia otras formas políticas de organización y administración de los bienes regionales (2012, p. 12). Así, la región presenta un conglomerado de proyectos de integración política poscomerciales y proyectos de bienestar transociales que reclaman los principios de cooperación y solidaridad (2012, p. 10), antes definidos por Riggirozzi (2010, p. 1) como colectivismo y socialismo. Recientemente, las autoras han reformulado y ampliado sus ideas para caracterizar al momento poshegemónico (Riggirozzi y Tussie, 2017).

Briceño-Ruiz y Ribeiro Hoffmann (2015) utilizan esta conceptualización para abordar la Unasur y revisitan diferentes alusiones a la noción de poshegemónico, marcando diferencias respecto de la noción de Acharya (2009) sobre un orden mundial poshegemónico y del regionalismo, así adjetivado por Telò (2007) en el marco de un sistema mundial turbulento y heterogéneo. No obstante, ellos no avanzan en una mayor precisión de qué entienden por este tipo de regionalismo y pareciera que retoman la de las autoras mencionadas en primera instancia. 
Al igual que los autores hasta ahora revisitados, también sitúan al tipo histórico con la nueva conformación de los escenarios nacionales (donde la correlación de fuerzas se inclina hacia proyectos desarrollistas, de bienestar y hasta de buen vivir) en el marco de los consensos con gobiernos neoliberales que se suman a construir un proyecto político más autonómico dado un cierto debilitamiento de la incidencia de la potencia hegemónica. El punto más contestado por la literatura ha sido la ausencia de una definición de hegemonía consistente que pudiera dar un andamiaje teórico más sustantivo a la caracterización, exceptuando a Riggirozzi y Tussie (2012) que retoman los aportes de Cox y Sinclair (1996). Un detallado análisis en torno a la hegemonía en los constructos de regionalismo poshegemónico y contrahegemónico se encuentra en Narea (2016).

\subsection{Otras propuestas de adjetivación}

El mapa de caracterizaciones sobre el tipo de regionalismo que se gesta en América Latina desde los años 2000 presenta una variedad y creatividad distintiva —que no se ha observado al analizar otras experiencias. A los tres ejemplos revisitados se adicionan las nociones de: regionalismo productivo y regionalismo social (Briceño-Ruiz, 2011), regionalismo inclusivo (Vazquez, 2011), regionalismo solidario (Perrotta, 2011; Perrotta y Porcelli, 2016a), regionalismo regulatorio (Perrotta, 2013, 2016a, 2016b) ${ }^{12}$, regionalismo segmentado (Malamud y Gardini, 2012), regionalismo modular (Gardini, 2015), regionalismo declarativo (Jenne, Schenoni, y Urdinez, 2017), regionalismo superpuesto (overlapping) (Gómez-Mera y Molinari, 2014; Malamud, 2013; Nolte, 2018), regionalismo a la carta (Quiliconi, 2014; Quiliconi y Espinoza, 2017), entre otros.

Excede los objetivos de este artículo realizar un análisis detallado de cada una de estas propuestas, si bien es posible delinear algunas reflexiones en el siguiente apartado.

\subsection{El regionalismo con adjetivos}

El regionalismo adjetivado (Perrotta y Porcelli, 2016b) alude a una discusión de la ciencia política debido a la proliferación de adjetivos para poder definir a las democracias de la tercera ola de democratización y, en especial, a las latinoamericanas. Collier y Levitsky (1998) revisitan ese fenómeno académico explicitando la tensión entre la necesidad de la diferenciación analítica y la validez conceptual que se ha resuelto con una sorprendente cantidad de democracias con adjetivos (1998, p. 100) como subtipos que modifican las definiciones de democracia y, en

12 Retomando a Hameri y Jayasuriya (2011). 
algunos casos, con características que se contradicen con definiciones mínimas y procedimentales del término. Al igual que estos autores, se retoma la propuesta de Sartori (1984) para lograr la diferenciación y evitar el estiramiento conceptual mediante el movimiento en una escala de abstracción ${ }^{13}$, resulta pertinente realizar algunas reflexiones en torno al regionalismo.

En primer lugar, a partir de las propuestas revisitadas, exceptuando los aportes del regionalismo regulatorio y regionalismo a la carta, cada caracterización se enfoca en analizar la particularidad desde la adjetivación sin prestar atención a la especificidad del regionalismo en su carácter procesual, histórico y multidimensional - $\mathrm{o}$, a lo sumo, se incorpora dentro del debate de las oleadas de regionalismo (Dabène, 2012b). Lo regulatorio del regionalismo, así como la posibilidad de escoger entre un menú de propuestas de proyectos, alude a la incidencia de la construcción de región sobre el nivel doméstico y sus vinculaciones tanto con intereses como con ideas y valores de diferentes actores (estatales y no estatales) en ese proceso, aportando así elementos tanto para el policy-making como el policy-analysis.

En segundo término, la adjetivación brinda descripciones en profundidad de tipos de construcción de región, con análisis sobre casos y propuestas de generalizaciones, pero no permite avanzar en explicaciones sobre $\mathrm{el}$ regionalismo, mucho menos avanzar en la comparación con otras experiencias. Ilustra esta afirmación el hecho de que se cuente con un mismo adjetivo al que se asignan significados divergentes para entender fenómenos diferentes — como el [nuevo] regionalismo estratégico que explica tres proyectos políticos regionales diferentes con diversas definiciones - y diferentes etiquetas que miran un mismo proceso - regionalismo poshegemónico y posliberal. Inclusive, los adjetivos explican más sobre el momento, ciclo o etapa en la región que el regionalismo y/o la integración en sí mismos.

Como corolario de lo anterior, en tercer término, queda desdibujada una característica central de la definición de integración regional que ha quedado olvidada: la integración regional (y/o el regionalismo) es instrumental. La adjetivación afirma esta idea pensando tipos históricos y casos específicos de regionalismo, pero no lo coloca como un tema visible para discutir la cuestión central: ¿qué es la integración regional?, ¿qué es el regionalismo?, ¿en qué se diferencian de las formas de cooperación, coordinación y concertación interestatal?, ¿cuál es

13 Esta escala propone una relación inversa entre la cantidad de casos a describir y el número de atributos relevantes. Cuanto menos atributos (y, por lo tanto, mayor abstracción) tiene el concepto, puede ser aplicado a más casos ubicándose en lo alto de la escala; mientras que una mayor diferenciación y especificidad en los atributos del concepto permite aplicarlo a menos casos y su ubicación será en lo bajo de la escala (Sartori, 1984). 
el rol asignado a la región para los Estados —en su inserción internacional como en el manejo de sus asuntos domésticos-y para los actores no estatales - como empresas, sindicatos, movimientos sociales en el reclamo de beneficios?, ¿cuáles son las disputas por el significado de la región?

Estas preguntas habilitan a comenzar una reflexión que permite subir en la escala de abstracción para evitar el estiramiento conceptual y así impide tener tantas definiciones como casos existentes, sin caer en la prescripción normativa de las teorías de la red central de producción de conocimiento.

\section{Discusión}

El campo de estudios de la integración regional —en su configuración mainstream como en las distintas periferias dependientes - no ha logrado saldar su rompecabezas nodal: ¿qué es la integración? ¿qué es el regionalismo? Otras preguntas de investigación menos problemáticas cuentan con teorizaciones y propuestas metodológicas creativas y validadas: el rol y la capacidad de agencia de los Estados y actores no estatales, las disputas por los sentidos y las identidades en la construcción de región, la funcionalidad de la región, principalmente. La notable producción teórica es sustantiva y rigurosa, mas esquiva del problema fundante del campo. Pero, aun con este carácter escurridizo y complejo se debe reflexionar y generar consensos mínimos de entendimiento sobre qué es la integración regional y el regionalismo. ${ }^{14}$

En virtud de ello, se propone recuperar un conjunto de referencias que brindan pistas para la construcción de una categoría amplia, que recoja la multiplicidad de experiencias evitando prescribir normativamente modelos de región-en-construcción y avance en una reflexión que recupere localidades desde una perspectiva decolonial, así como aborde las asimetrías y los procesos de desigualdad existentes —quizás desde posturas feministas. La selección de definiciones es un primer paso en la búsqueda de la diferenciación analítica y la validez conceptual.

El planteo fundante de Ernst Haas (1958) es un necesario punto de partida al concebir la integración como:

[...] el proceso por el cual los distintos actores políticos en variados escenarios nacionales son persuadidos a cambiar sus lealtades, expectativas y actividades

14 Nótese que durante todo el trabajo se ha aludido a ambos conceptos de manera conjunta, como si fueran intercambiables, si bien se ha mencionado que el regionalismo reemplaza a la integración y esto genera una pérdida de precisión conceptual que deriva en la actual situación de adjetivación. Ambos conceptos no son intercambiables y ello es menester de un artículo en sí mismo en otra ocasión. 
políticas hacia un nuevo centro, cuyas instituciones poseen o demandan jurisdicción sobre los Estados nación preexistentes. El resultado final [...] es una nueva comunidad política, superpuesta sobre las preexistentes. (Haas, 1958, p. 16)

Esta definición es apenas diferente respecto de la propuesta de otro neofuncionalista: Lindberg (1963, p. 6) sutilmente cuestiona el cambio de lealtades para concentrarse en la persuasión a modificar expectativas y actividades únicamente.

En la red de conocimiento local de los autores, Juan Carlos Puig (1986) propone una definición que le permite recuperar y discutir a la luz de América Latina con el planteo anterior. La integración es:

[...] un fenómeno social según el cual dos o más grupos humanos [(Estados, sociedades, empresas, comunidad internacional)] adoptan una regulación permanente de determinadas materias que hasta ese momento pertenecían a su exclusiva competencia (o dominio reservado) [...] se trata de conductas que tienen como propósito lograr que los grupos sociales en cuestión renuncien en determinadas materias a la actuación individual para hacerlo en forma conjunta y con sentido de permanencia. (Puig, 1986, p. 41)

De manera explícita, indica que la integración es instrumental:

[...] la integración en sí misma tampoco es autonomizante. En el fondo es instrumental, y su sentido dependerá del objetivo que se fije. Tal vez porque los objetivos no fueron propiamente autonómicos es que no han avanzado decididamente los procesos de integración en América Latina. Y por eso también sea posible que pretensiones autonomistas, ineludiblemente competitivas en lo económico y lo estratégico con las naciones industrializadas, no pueden sostenerse en América Latina sin modelos de desarrollo interno congruentes y sin estar afincadas en una solidaridad estratégica, que no es ocasional y especulativa, con países que aspiran a lo mismo. (Puig, 1980, p. 154-155)

Si la integración regional es instrumental, entonces, es posible evidenciar formas o proyectos en relación con las metas que los actores que deciden integrarse. En el caso de los Estados que buscan mejorar sus márgenes de maniobra - en línea con su propuesta de autonomía heterodoxa-, ese tipo de integración es la solidaria.

[Es] posible [la integración por] la vía de los valores compartidos y de las alianzas que se podrían concretar en su defensa conjunta. [...] A pesar de las diferencias existentes en materia del potencial, hay valores que la inmensa mayoría de los latinoamericanos - élites y pueblos - compartimos. Uno de ellos es el de la autonomía. Todos nuestros países tratan de ser autónomos. Podrá haber discrepancias respecto de la forma y de la intensidad del impulso autonómico y de las estrategias aplicables, pero no se puede poner en duda el objetivo que se persigue, a pesar de 
las diferencias estructurales y de la diversidad de orientaciones políticas, es el de acentuar la capacidad de decisión nacional. (Puig, 1986, p. 45)

La integración solidaria, entonces, se fundamenta en alianzas de «Estados decididos a conseguir determinados objetivos sectoriales, pero que se fundamentan en valores compartidos, entre los que descuella el de autonomía» (Puig, 1986, p. 59-60).

La alusión a la integración como instrumental y volitiva también se ha expresado en las conceptualizaciones desde el estructuralismo económico latinoamericano. Aldo Ferrer, por ejemplo, al caracterizar la densidad regional indica que:

El proceso de integración regional no se reduce a fijar reglas para la integración entre los países miembro y establecer políticas públicas de alcance comunitario. Abarca y está condicionado, asimismo, por las decisiones propias de cada país en la construcción de su desarrollo nacional, las acciones conjuntas para transformar la inserción de la región en el escenario global y resolver las asimetrías existentes. Estas circunstancias [...] no inhabilitan la validez del proyecto [regional] pero caracterizan su complejidad y condicionan la estrategia integracionista. (Ferrer, 2008, p. 8-9)

La síntesis de los objetivos instrumentales de la integración ha sido delimitada en términos de la consecución de autonomía política y desarrollo económico por José Paradiso (2011), retomado posteriormente por varios autores (Briceño-Ruiz, 2012). A la vez, el reconocimiento del carácter volitivo e instrumental permite periodizar en olas los proyectos de integración que se desarrollan en el tiempo.

En esta línea ha trabajado Dabène $(2012 a, 2012 b)$ las diferentes oleadas y ciclos (de politización) de la integración, la que define como:

[...] el proceso histórico de aumento de los niveles de interacción entre unidades políticas (subnacionales, nacionales o transnacionales), a partir de actores que comparten ideas comunes, fijan objetivos y definen los métodos para alcanzarlos; $y$, al hacer esto, contribuyen a la construcción de la región. (Dabène, 2009, p. 10)

Estos aportes para pensar la integración permiten trazar un puente con las conceptualizaciones del regionalismo (de las TNR), ya que incorporan la diversidad de actores, niveles y agendas de construcción de la región, que siempre es una construcción social políticamente contestada (Hurrell, 1995b) por lo que emerge de decisiones deliberadas de los actores gubernamentales como de la interacción social y conlleva a la creación de instituciones (de diferente tipo). No obstante, la característica distintiva de las TNR es, precisamente, cierta confusión conceptual por la utilización de términos similares como región, regionalización y regionalismo - mientras se descarta la categoría integración. Pese a que varios autores excusan la falta de delimitación conceptual en el hecho de que estos procesos son 
un fenómeno emergente (Fawcett y Hurrell, 1995; Hettne y Söderbaum, 1998), cabe preguntarse cuán emergente (o nuevo) es un fenómeno que surgió entre los años cincuenta y sesenta en diferentes partes del mundo. Lo nuevo no es el fenómeno integración o regionalismo; lo nuevo son las reconfiguraciones que experimenta dadas las coyunturas internacionales, nacionales y locales —en línea con las metas que los actores que conducen la integración se proponen.

En líneas generales, la regionalización se refiere al proceso que acompaña el aumento de la interacción y la actividad al interior de la región, mientras que el regionalismo es un proyecto político. La diferencia clave entre ambos es que la regionalización supone un acercamiento de abajo hacia arriba (bottom-up), caracterizado por las interacciones económicas y sociales sin dirección entre actores no estatales - ya sean individuos, compañías u organizaciones no gubernamentales-, y el regionalismo implica un acercamiento de arriba hacia abajo (top-down) en tanto refiere al nivel de toma de decisiones de políticas en diferentes áreas de cooperación (economía, paz, seguridad, etc.) (Fawcett y Gandois, 2010). Así, parecería que la integración regional surge de la combinación de ambas dinámicas.

Otra forma de definir el regionalismo es diseccionándolo. Hurrell (1995b) lo despliega en cinco categorías: regionalización, identidad y conciencia regional, cooperación regional interestatal y cohesión regional; mientras que Hettne y Söderbaum (2002) proponen cinco niveles de regionidad (regioness) ${ }^{15}$ : espacio regional, complejo regional, sociedad regional, comunidad regional y Estado-región. Estas propuestas permiten abordar variadas cuestiones, más agregan dificultad para identificar los atributos salientes del regionalismo y la integración.

En vistas a reflexionar sobre estas dificultades — cómo generar un diálogo entre las dos escuelas de la red central y cuáles son los atributos de consenso de la categoría a analizar-, resulta pertinente recuperar algunas aclaraciones que se han realizado sobre los estudios del regionalismo comparado, especialmente la que refiere a la falta de claridad conceptual, la ausencia de un consenso en torno a la variable dependiente, y los problemas para articular las dos escuelas centrales. Söderbaum y De Lombaerde (2013) destacan problemas en cuatro dimensiones: una disciplinar, otra vinculada a los casos por regiones geográficas, otra entre tradiciones teóricas y una última entre formas de regionalismo en base a agendas sectoriales. Lo que socava la construcción de conocimiento sobre el fenómeno

15 La regionidad es «el proceso por el cual un área geográfica se transforma de un objeto pasivo a un sujeto activo, capaz de articular los intereses transnacionales de la región emergente [...] Regionness implica, por tanto, que una región puede ser 'más o menos'. El nivel de regionness puede tanto aumentar como disminuir» (Hettne y Söderbaum, 2002, p. 38). 
—en general - y sobre su comparación — en particular — es la falta de consensos mínimos de los atributos de ese objeto a observar.

De manera preliminar, para comenzar a pensar estos atributos y generar un consenso al interior del campo, es posible afirmar que, si bien la diversa gama de experiencias históricas de integración regional en todo el mundo permite señalar que no existe una forma única de encaminar proyectos de construcción de región, estas variadas experiencias comparten un conjunto de características comunes que las diferencian de las formas de cooperación, coordinación o concertación interestatales: la decisión de actores sociales interesados (estatales o no estatales) en crear instituciones comunes para adoptar decisiones consensuadas que generan normas que afectan el nivel nacional de regulación de políticas. Por supuesto, la puesta en común y la sesión de soberanía no ha de ser idéntica en todos los casos, la regulación regional sobre la agenda doméstica puede variar en profundidad y alcance, y no todos los acuerdos avanzan necesariamente en la conformación de una narrativa común que proporcione un horizonte de significado compartido sobre el proyecto político subyacente que erige a la región en tanto actor.

Esta propuesta recoge, entonces, la característica central de la integración (y el regionalismo) como instrumental y volitivo, donde una plétora de actores incide en su construcción (para buscarla, moldearla) a partir de estas metas (susceptibles de ser planteadas como intereses, pero también como ideas e identidades) y la percepción de que éstas serán alcanzadas.

\section{Conclusiones. En pos de una agenda integral para el campo de estudios: formación, investigación e intervención}

En este artículo se identificaron un conjunto de interrogantes nodales al campo de estudios y que permanecen poco visibilizados y, algunos, sin respuesta dado el problema de la adjetivación que se argumentó: ¿qué es la integración regional?, ¿qué es el regionalismo?, ¿en qué se diferencian de las formas de cooperación, coordinación y concertación interestatal?, ¿cuál es el rol asignado a la región para los Estados - en su inserción internacional y en el manejo de sus asuntos domésticos- y los actores no estatales - como empresas, sindicatos, movimientos sociales en el reclamo de beneficios?, ¿cuáles son las disputas por el significado de la región?

Exceptuando los dos primeros, desde el conocimiento académico disponible y en circulación (ya sea central o periférico), existen propuestas que permiten ir arrojando luz sobre el proceso de construcción de región. No se desconoce aquí 
todo ese trabajo ni se reniega de las propuestas de los colegas para explicar diferentes aristas del fenómeno. Sin embargo, aún queda irresuelto poder discernir, por ejemplo, qué tiene en común — solo pensando en América Latina - la Alianza del Pacífico con la Unasur o con el Mercosur. Es decir, qué atributos explican el proceso más allá de su adjetivación. Por lo tanto, una agenda propositiva ha de comenzar por alcanzar esos entendimientos mínimos sobre el objeto de estudio del campo de conocimiento.

Al afirmar que el regionalismo es lo que la academia hace de él, se realiza un planteo sobre las condiciones de producción intelectual vigentes en el marco de una geopolítica del conocimiento que cuenta con redes centrales y periféricas. Por supuesto, no es nuevo afirmar que son los actores del campo los que generan sus conceptos. El punto para destacar es preguntarse sobre las condiciones de producción de esos conceptos y las consecuencias que eso ha acarreado en el estudio del regionalismo y la integración. Entre esas consecuencias se destaca la excesiva adjetivación como parte de una carrera por imponer categorías que puedan ser diseminadas y validadas rápidamente. Tampoco es un debate novedoso en las disciplinas discutir centros y periferias del conocimiento; es decir, la distribución desigual y asimétrica del poder y sus impactos en la ciencia. En la ciencia social, la visibilización de Nortes y Sures es de larga data, como también lo es la reflexión profunda sobre la imposición de un patrón colonial/moderno/eurocéntrico (Lander, 2003; Quijano, 2010) sobre las diferentes formas de conocer. En la disciplina de las relaciones internacionales — de la que se nutre en buena medida el campo de estudios de la integración y el regionalismo_-, la búsqueda de su descolonización ha sido más bien reciente (respecto de otras disciplinas de las ciencias sociales y humanidades $)^{16}$; teniendo como un primer paso significativo la llamada a incorporar las voces locales en el centro disciplinar (Acharya, 2014) — se conoce como el acercamiento entre el Sur global y el Norte global-.

Sin ánimos de entrar en un debate sobre las relaciones internacionales de conocimiento (nótese que no se alude al fenómeno de internacionalización de la ciencia y la universidad), lo que se ha visibilizado en este trabajo es la actividad internacional colaborativa en pos de avanzar en el estudio del objeto. La división Norte y Sur no es cabal porque existen Sures en el Norte y Nortes en el Sur; pensarlo en términos de redes de conocimiento centrales y periféricas despeja el elemento geográfico y permite visibilizar la densa y compleja trama de las conexiones y colaboraciones científicas a nivel global; agregar un componente de discusión que parta desde la deconstrucción disciplinar y que avance en perspec-

16 Que sea un objetivo reciente no implica que el estudio de las RI desde perspectivas descoloniales sea reciente. Al contrario, lo que se quiere señalar es que debates vedados o marginalizados hasta tiempos recientes, comienzan a tener mayor presencia en el centro de la escena de la disciplina. 
tivas descoloniales es un paso ineludible para visibilizar - y detener- las presiones normativas de quienes detentan el poder en la producción y divulgación de conocimiento. Por este motivo se ha dedicado atención en la segunda sección a estas discusiones, a las que se puede sumar - desde el campo de la ciencia, tecnología y sociedad (CTS) - las reflexiones en torno a la necesidad de provincializar el conocimiento para saldar las miradas parroquiales (Law y Lin, 2017).

Si el regionalismo es lo que los académicos y las académicas hacen de él, entonces, se deben revisitar y refundar las prácticas académicas en un sentido integral. Desde el momento de agitación conceptual, lo que académicos y académicas han realizado es centrarse en los elementos propios de cada caso novedoso: la adjetivación produjo un sinfín de $n=1$ que replicó el problema de las teorías europeas de la integración de explicar un único caso, pero a la vez no avanzó (¿aún?) en el diálogo entre casos, tal como prometió el regionalismo comparado. Desde el punto de vista del conocimiento, una propuesta que se formula - sin ánimos de entrar en la nostalgia de «todo pasado fue mejor»- es la de recuperar algunos aportes más clásicos, así como otros olvidados (no visibilizados masivamente). Para comenzar una reflexión hay que tener un punto de partida, al menos para discutir.

No obstante, se postula que el campo de estudios ha de encaminar una estrategia integral; esto es, en los planos de la formación (de grado y posgrado), de la investigación y de la intervención (política). En los dos primeros, atendiendo a las discusiones sobre las presiones de las condiciones de producción intelectual, que llevan a diseminar las mismas categorías y metodologías como formas de buscar validación y legitimidad en los espacios de evaluación y divulgación de la ciencia de excelencia. ${ }^{17}$ Las presiones sobre la figura del profesor-investigador llevan a que este elabore contenidos curriculares en función de las jerarquías de poder del campo (visibilizando a los más visibles), por un lado; y que se indique a los estudiantes que la búsqueda del conocimiento de excelencia está en un conjunto de publicaciones de acceso restringido (y no en otros formatos de divulgación). Esto genera un problema en el campo, como expresión de un problema mayor de formación crítica de especialistas y analistas. Además, su propia estrategia de supervivencia como trabajador/a de la ciencia depende de su validación en estos circuitos, lo que retroalimenta el sistema asimétrico de conocimiento y genera su autorreproducción.

Finalmente, el eje de intervención no ha de ser soslayado: si la integración y el regionalismo son instrumentales, la definición de metas es un ejercicio eminentemente político y permanentemente contestado. Se disputa el proyecto de

17 Véase: Vessuri, Guédon, y Cetto (2014) y Perrotta (2017). 
integración, en el mismo modo en que se disputan los sentidos de la construcción de región y, por lo tanto, de los problemas cognitivos de esa región — que afectan el nivel de producción de conocimiento y que implica una relación cercana con la praxis. En otros términos, saldar las presiones normativas de la red central implica discutir el policy-making como el policy analysis. Los y las fundadoras del campo de estudios en América Latina tuvieron un doble rol de intelectual y político. En este escenario de desconcierto, más que nunca se debe repensar el estudio del regionalismo en la discusión intraacadémica como con esos otros actores que inciden en la construcción de región. Esto es así porque, lo que la academia hace del regionalismo no solamente implica que construye los conceptos sobre los que se articula el debate académico, sino que tiene, especialmente, capacidad normativa sobre el regionalismo existente. Lo que la academia dice sobre el regionalismo es performativo, al nominar genera realidad.

\section{Bibliografía}

Aboy Carlés, G. (2004). Repensanso el Populismo. En K. Weyland, C. De la Torre, G. Aboy Carlés, y H. Ibarra (Eds.), Releer los Populismos (pp. 79-126). Quito, Ecuador: Centro Andino de Acción Popular.

ACHARYA, A. (2004). How ideas spread: Whose norms matter? Norm localization and institutional change in Asian regionalism. International organization, 58(2), 239-275.

ACHARYA, A. (2009). Regional Worlds in a post-hegemonic era, Working Paper. Burdeos Francia: Cashier de SPIRIT/SPIRIT.

ACHARYA, A. (2011). Norm subsidiarity and regional orders: sovereignty, regionalism, and rule-making in the third world. International Studies Quarterly, 55(1), 95-123.

ACHARYA, A. (2014). Global International Relations (IR) and Regional Worlds A New Agenda for International Studies. International Studies Quarterly, 58(4), 647-659.

AllisOn, L. (2015). The EU, ASEAN and interregionalism: regionalism support and norm diffusion between the EU and ASEAN. Londres, Reino Unido: Palgrave Macmillan UK.

Aponte García, M., y AmÉzQuita Puntiel, G. (2015). El aLBA-TCP. Origen y fruto del nuevo regionalismo latinoamericano y caribeño. Buenos Aires, Argentina: CLACSO. 
BACH, D. C. (2015). Regionalism in Africa: Genealogies, institutions and trans-state networks. Abingdon, Reino Unido: Routledge.

Bhagwati, J., y Panagariya, A. (1999). Preferential trading areas and multilateralism-strangers, friends, or foes. En J. Bhagwati, P. Krishna y A. Panagariya (Eds.), Trading Blocs: Alternative Approaches to Analyzing Preferential Trade Agreements (pp. 33-100). Cambridge: MIT Press.

BID (2002). El nuevo regionalismo en América Latina. En BID (Ed.), Mas allá de las fronteras: el nuevo regionalismo en América latina (pp. 27-65). Buenos Aires, Argentina: Banco Interamericano de Desarrollo.

Bizzozero, L. (2011). América Latina a inicios de la segunda década del siglo Xxi: entre el regionalismo estratégico y la regionalización fragmentada. Revista Brasileira de Politica Internacional, 54(1), 29-43.

BöRzEL, T., y Risse, T. (2000). When Europe Hits Home: Europeization and Domestic Change. Florencia, Italia: Instituto Universitario Europeo.

Börzel, T., y Risse, T. (2009). Diffusing (Inter-) Regionalism. The EU as a Model of Regional Integration. Working Paper KFG The Transformative Power of Europe, 26.

Briceño-Ruiz, J., y Ribeiro Hoffmann, A. (2015). Post-hegemonic regionalism, Unasur, and the reconfiguration of regional cooperation in South America. Canadian Journal of Latin American and Caribbean Studies / Revue canadienne des études latino-américaines et caraïbes, 40(1), 48-62.

BRICEÑo-RuIZ, J. (2007). Strategic regionalism and regional social policy in the FTAA process. Global Social Policy, 7(3), 294-315.

BRICEÑo-RuIZ, J. (2010). El regionalismo estratégico en el Tratado de Libre Comercio de América del Norte (TLCAN). AD Universa revista de Relaciones Internacionales, 1(1), 13-50.

BRICEÑo-RUIZ, J. (2011). Del regionalismo estratégico al regionalismo social y productivo. Las transformaciones del modelo de integración en el Mercosur. En J. Briceño-Ruiz (Ed.), El Mercosur y las complejidades de la integración regional. Buenos Aires, Argentina: TESEO.

BriceÑo-Ruiz, J. (2012). Autonomía y desarrollo en el pensamiento integracionista latinoamericano. En J. Briceño-Ruiz, A. Rivarola Puntigliano y Á. Casas Gragea (Eds.), Integración Latinoamericana y Caribeña (pp. 27-78). Buenos Aires, Argentina: Fondo de Cultura Económica.

CePAl. (1990). Transformación productiva con equidad. La tarea prioritaria de América Latina y el Caribe en los años noventa Santiago de Chile, Chile: CEPAL. 
ClosA, C. (2015). Mainstreaming Regionalism. EUI Working Paper, Robert Schuman Centre for Advanced Studies Research Paper n. ${ }^{\circ}$ RSCAS 2015/12. RSCAS 2015/12, doi <http://dx.doi.org/10.2139/ssrn.2559777>.

Collier, D., y Levitsky, S. (1998). Democracia con adjetivos. Innovación conceptual en la investigación comparativa. Ágora, 8, 99-122.

Cox, R. W., y SinclaIR, T. J. (1996). Approaches to World Order. Cambridge, Reino Unido: Cambridge University Press.

DABÈne, O. (2009). The politics of regional integration in Latin America: theoretical and comparative explorations. Nueva York, EE. UU.: Palgrave Macmillan.

DABÈne, O. (2012a). Consistency and Resilience through Cycles of Repoliticization. En P. Riggirozzi, y D. Tussie (Eds.), The Rise of Post-Hegemonic Regionalism (pp. 41-64). Berlín, Alemania: Springer.

DABÈNE, O. (mayo de 2012b). Explaining Latin Americas fourth wave of regionalism. Regional integration of a third kind. Congreso de Latin American Studies Association (LASA) Panel «Waves of change in Latin America. History and Politics». Congreso llevado a cabo en San Francisco, EE. UU.

De Melo, J., y Panagariya, A. (1995). New dimensions in regional integration: Cambridge, Reino Unido: University Press.

Deblock, C., y Brunelle, D. (1993). Une intégration régionale stratégique: le cas nord-américain. Études internationales, 24(3), 595-629.

Der Derian, J. (1989). The Boundaries of Knowledge and Power in International Relations. En J. Der Derian y M. Shapiro (Eds.), International/Intertextual Relations: Postmodern Readings of World Politics (pp. 3-8). Nueva York, EE. UU.: Lexignton Books.

Diez, T. (2005). Constructing the Self and Changing Others: Reconsidering 'Normative Power Europe'. Millennium, 33(3), 613-636.

Fawcett, L., y Gandois, H. (2010). Regionalism in Africa and the Middle East: Implications for EU Studies. Journal of European Integration, 32(6), 617-636.

FAWCETT, L., y HurRell, A. (1995). Regionalism in world politics regional organization and international order. Nueva York, EE. UU.: Oxford University Press.

Ferrer, A. (2008). Densidad nacional y densidad regional. Revista Densidades, 1, $7-11$.

Frankel, J., Stein, E., y Wei, S.-j. (1995). Trading blocs and the Americas: The natural, the unnatural, and the super-natural. Journal of Development Economics, 47(1), 61-95. 
GARDINI, G. L. (2015). Towards modular regionalism: the proliferation of Latin American cooperation. Revista Brasileira de Política Internacional, 58(1), 210-229.

Gómez-Mera, L., y Molinari, A. (2014). Overlapping institutions, learning, and dispute initiation in regional trade agreements: evidence from South America. International Studies Quarterly, 58(2), 269-281.

HaAs, E. (1958). The Uniting of Europe: political, social and economic forces (19501957). Stanford, EE. UU.: Stanford University Press.

HaAs, E. (1976). Turbulent fields and the theory of regional integration. International Organization, 30(2), 173-212.

HaAstrup, T. (2013). EU as Mentor? Promoting Regionalism as External Relations Practice in EU-Africa Relations. Journal of European Integration, 35(7), 785-800.

HAMERI, S., y JAYASURIYA, K. (2011). Regulatory Regionalism and the Dynamics of Territorial Politics: The Case of the Asia-Pacific Region. Political Studies, 59(1), 20-37.

Hettne, B., y SöDerbaum, F. (1998). The new regionalism approach. Politeia, 17(3), 6-21.

Hettne, B., y Söderbaum, F. (2002). Theorising the rise of Regionness. En S. Breslin, C. Hughes, N. Phillips y B. Rosamond (Eds.), New Regionalisms in the Global Political Economy. Theories and cases (pp. 33-47). Londres, Reino Unido: Routledge.

Hurrell, A. (1995a). Explaining the Resurgence of Regionalism in World Politics. Review of International Studies, 21(4), 331-368.

Hurrell, A. (1995b). Regionalism in Theoretical Perspective. En L. Fawcett y A. Hurrell (Eds.), Regionalism in World Politics (pp. 31-71). Oxford, Reino Unido: Oxford University Press.

Hurrell, A. (2007). One world? Many worlds? The place of regions in the study of international society. International Affairs, 83(1), 127-146.

JeNne, N., SCHENONI, L. L., y URdinez, F. (2017). Of words and deeds: Latin American declaratory regionalism, 1994-2014. Cambridge Review of International Affairs, 30(2-3), 195-215.

Jetschke, A., y Lenz, T. (2013). Does Regionalism Diffuse? A New Research Agenda for the study of Regional Organizations. Journal of European Public Policy, 20(4), 626-637.

LAClAU, E. (2006). Consideraciones sobre el populismo latinoamericano. Cuadernos del CENDES, 23(62), 117-122. 
LANDER, E. (2003). La colonialidad del saber: eurocentrismo y Ciencias Sociales. Buenos Aires: CLACSO.

LAW, J., y LIN, W.-y. (2017). Provincializing sts: Postcoloniality, Symmetry, and Method. East Asian Science, Technology and Society: An International Journal, 11(2), 211-227.

LINDBERG, L. (1963). The political dynamics of European Economic Integration. Stanford, EE. UU.: Stanford University Press.

Malamud, A. (2013). Overlapping regionalism, no integration: conceptual issues and the Latin American experiences, RSCAS Working Paper 2013/20. Florencia, Italia: European University Institute.

Malamud, A., y Gardini, G. L. (2012). Has regionalism peaked? The Latin American quagmire and its lessons. The International Spectator, 47(1), 116-133.

Manners, I. (2002). Normative Power Europe: A Contradiction in Terms? JCMS. Journal of Common Market Studies, 40(2), 235-258.

Manners, I. (2006). The European Union as a Normative Power: A Response to Thomas Diez. Millennium, 35(1), 167-180.

MANNERS, I. (2008). The normative ethics of the European Union. International Affairs, 84(1), 45-60.

Manners, I. (2015). Sociology of Knowledge and Production of Normative Power in the European Union's External Actions. Journal of European Integration, 37(2), 299-318.

Mattheis, F. (2017). Repositioning Europe in the study of regions: comparative regionalism, interregionalism and decentred regionalism. Journal of European Integration, 39(4), 477-482.

Merlingen, M. (2007). Everything Is Dangerous: A Critique of 'Normative Power Europe'. Security Dialogue, 38(4), 435-453.

Moreira, C., Raus, D., y Leyton, J. C. G. (2008). La nueva política en América Latina: rupturas y continuidades. Montevideo, Uruguay: Ediciones Trilce.

Motta Veiga, P. d., y Ríos, S. (2007). O regionalismo pós-liberal, na América do Sul: origens, iniciativas e dilemas. Santiago de Chile, Chile: Cepal.

NAREA, M. (2016). ¿Regionalismo poshegemónico o contrahegemónico?: una revisión de los debates teóricos actuales [tesis de maestría]. Universidad Andina Simón Bolívar, Sede Ecuador. Área de Estudios Sociales y Globales, Quito, Ecuador. 
Nolte, D. (2018). Costs and Benefits of Overlapping Regional Organizations in Latin America: The Case of the OAS and Unasur. Latin American Politics and Society, 60(1), 128-153.

PANAgARIYA, A. (1992). The new regionalism in trade policy. Washington, DC, EE. UU.: The World Bank.

PARAdiso, J. (2011). El ideal unificador en América Latina. Economía, sociedad y politica en los procesos de integración. Caseros, Argentina: EDUNTREF [mimeo].

Perrotta, D. (2011). La integración regional de la educación superior en el Mercosur en el marco de la orientación general del bloque y la tensión entre un modelo solidario y otro competitivo: el caso de los programas regionales de acreditación de carreras de grado (del MEXA al ARCU-SUR, 1998-2008). Buenos Aires, Argentina: Flacso.

Perrotta, D. (24 y 25 de octubre de 2012). La integración regional en América del Sur como objeto de estudio: ¿en pos de la construcción de un campo? III Jornadas de Relaciones Internacionales. Área de Relaciones Internacionales FLACSO Argentina. Congreso llevado a cabo en Buenos Aires, Argentina.

Perrotta, D. (2013). El regionalismo de la educación superior en el proceso de integración regional del Mercosur: políticas de coordinación, complementación, convergencia y armonización en las iniciativas de acreditación de la calidad de carreras de grado (1998-2012) [tesis doctoral]. Facultad Latinoamericana de Ciencias Sociales (Flacso), sede académica Argentina, Buenos Aires, Argentina.

Perrotta, D. (2016a). Mercosur, regionalismo regulatorio y gobernanza de la educación superior. Relaciones Internacionales, 25(51), 21-42.

Perrotta, D. (2016b). Mercosur, regulatory regionalism and contesting projects of higher education governance. En S. Robertson, K. Olds, R. Dale y Q. A. Dang (Eds.), Global Regionalisms and Higher Education. Londres, Reino Unido: Edward Elgar.

Perrotta, D. (2017). Universidad y geopolítica del conocimiento. Revista Ciencias Sociales, 94, 50-57.

Perrotta, D. (2018). El campo de estudios de la integración regional y su aporte a la disciplina de las Relaciones Internacionales: una mirada desde América Latina. Relaciones Internacionales, 38, 9-39.

Perrotta, D., y Porcelli, E. (2016a). Mercosur 25 años: desafíos en su nueva etapa. Márgenes. Revista de Economía Política, II(2), 53-72. 
Perrotta, D., y Porcelli, E. (2016b). 'Regionalismo adjetivado': desafíos teóricos para la comprensión de los procesos de construcción de región en América Latina. CEAP.

Puchala, D. J. (1971). Of blind men, elephants and international integration. JCMS: Journal of Common Market Studies, 10(3), 267-284.

Puig, J. C. (1980). Doctrinas internacionales y autonomía latinoamericana. Caracas, Venezuela: Universidad Simón Bolívar, Instituto de Altos Estudios de América Latina, Fundación Bicentenario de Simón Bolívar.

Puig, J. C. (1986). Integración y Autonomía en América Latina en las postrimerías del siglo xx. Integración Latinoamericana, 11(109), 40-62.

QuiJano, A. (2010). La crisis del horizonte de sentido colonial/moderno/eurocentrado. Casa de las Américas, 259-260, 4-25.

Quiliconi, C. (2014). Atlántico versus Pacífico: Las alternativas en competencia de la integración comercial en América Latina. Relaciones Internacionales, 23(47), 165-184.

QuiLiCONI, C., y EsPINOZA, R. S. (2017). Latin American Integration: Regionalism àla Carte in a Multipolar World? Colombia Internacional, 92, 15-41.

Riggirozzi, P. (2010). Crisis, Resilience and transformation: The Changing Architecture of Regionalism in Latin America. Congreso Annual meeting of the Theory vs. Policy. Congreso llevado a cabo en, Nueva Orleans, EE. UU.

RiggirozZI, P. (2012). Region, regionness and regionalism in Latin America: Towards a new synthesis. New Political Economy, 17(4), 421-443.

Riggirozzi, P., y Tussie, D. (2012). The Rise of Post-Hegemonic Regionalism: The Case of Latin America (Vol. 4). Dordrecht, Países Bajos: Springer.

Riggirozzi, P., y Tussie, D. (2017). Rethinking our region in a post-hegemonic moment. En J. Briceño-Ruiz y I. Morales (Eds.), Post-Hegemonic Regionalism in the Americas. Towards a Pacific vs. Atlantic divide (pp. 16-31). Nueva York, EE. UU.: Routledge.

SADER, E. (2009). El nuevo topo. Los caminos de la izquierda Latinoamericana. Buenos Aires, Argentina: Siglo XXI - CLACSO.

Sanahuja, J. A. (2008). Del 'regionalismo abierto' al 'regionalismo post liberal'. Crisis y cambio en la integración en América Latina y el Caribe. En L. Martínez, L. Peña y M. Vazquez (Eds.), Anuario de la integración regional de América Latina y el Gran Caribe 2008-2009. Buenos Aires, Argentina: CRIES. 
Sanahuja, J. A. (2012). Post-liberal Regionalism in South America: The case of Unasur. RSCAS Working Papers, 5. Florencia, Italia: RSCAS.

Sanahuja, J. A. (2016). Regionalismo e integración en América Latina: de la fractura Atlántico-Pacífico a los retos de una globalización en crisis. Pensamiento propio, 21(44), 29-76.

Sartori, G. (1984). La política. Lógica y método en las Ciencias Sociales. México DF, México: Fondo de Cultura Económica.

SJuRSEN, H. (2006). The EU as a 'normative'power: how can this be? Journal of European public policy, 13(2), 235-251.

Söderbaum, F. (2016). Rethinking Regionalism. Nueva York, EE. UU.: Palgrave.

Söderbaum, F., y De Lombaerde, P. (2013). Regionalism: Revisions of Classical Regional Integration (1970-1990). Nueva York, EE. UU.: Sage.

Staeger, U. (2016). Africa-eu Relations and Normative Power Europe: A Decolonial Pan-African Critique. JCMS: Journal of Common Market Studies, 54(4), 981-998.

Telò, M. (2007). Introduction: Globalization, new regionalism and the role of the European Union. En M. Telò (Ed.), European Union and New Regionalism (pp. 25-46). Nueva York, EE. UU.: Routledge.

VAzQuez, M. (2011). El Mercosur social. Cambio político y nueva identidad para el proceso de integración regional en América del Sur. En G. Caetano (Ed.), Mercosur 20 años (pp. 165-187). Montevideo, Uruguay: CEFIR.

Vessuri, H., Guédon, J. C., y Cetto, A. M. (2014). Excellence or quality? Impact of the current competition regime on science and scientific publishing in Latin America and its implications for development. Current Sociology, 62(5), 647-665.

VILAS, C. (2005). La izquierda latinoamericana y el surgimiento de regímenes nacional-populares. Nueva Sociedad, 197, 84-99.

VILAS, C. (2008). La revalorización del Estado después del 'Consenso de Washington’. ¿Hacia atrás o hacia adelante? En A. Chaparro Amaya, C. Galindo Hernández y A. M. Sallenave (Eds.), Estado, democracia y populismo en América Latina (pp. 144-172). Buenos Aires, Argentina: CLACSO.

Vivares, E., y Dolcetti-Marcolini, M. (2016). Two regionalisms, two Latin Americas or beyond Latin America? Contributions from a critical and decolonial IPE. Third World Quarterly, 37(5), 866-882.

Vivares, E., Lombardo, P. T., y CVETICH, K. (2014). Enfoques y cárceles conceptuales en el entendimiento de los nuevos regionalismos latinoamericanos. En A. 
Bonilla y I. Álvarez (Eds.), Desafios estratégicos del regionalismo contemporáneo: Celac e Iberoamérica (pp. 21-46). San José, Costa Rica: FLACSO.

Warleigh-LaCK, A. (2006). Towards a Conceptual Framework for Regionalisation: Bridging 'New Regionalism' and 'Integration Theory'. Review of International Political Economy, 13(5), 750-771.

Warleigh-Lack, A., y Van Langenhove, L. (2010). Rethinking EU Studies: The Contribution of Comparative Regionalism. Journal of European Integration, 32(6), 541-562.

Los autores realizaron igual contribución en la elaboración del artículo. 